\title{
The Study of Banking System Functionality Based on Data Envelopment Analysis (DEA) Method: A Case Study in Keshavarzi Banks in Kurdistan Province
}

\author{
Fariba Najafi \\ MA in Business Management, Sanandaj branch, Islamic Azad university, Sanandaj, Iran
}

\author{
Doi:10.5901/mjss.2015.v6n6s2p547
}

\section{Abstract}

This project has concentrated on technical evaluation and scales of Keshavarzi Bank in Kurdistan Province. To access this objective, descriptive and survey research has been used. In this order, different check lists of research input such as operational, non- operational and investment costs, industrial criterion, agricultural criterion, cite condition, branch ranking and the rate of literacy and also the research output including different kinds of deposits, delivered facilities, income and function have been collected. The studied society of this project is the whole 42 branches of Keshavarzi Banks in Kurdistan Province. Using the Data Envelopment Analysis and CCR and BCC models, the scale and technical productivity of the branches have been studied. Also the hierarchical analysis has been used to determine the importance coefficient of the research outputs. The results of this research shows that 25 out of 42 branches of Keshavarzi Banks have technical productivity based on CCR model and 16 branches based on BCC model have both the scale and technical productivity. The branches of Quorveh, Bijar, divandareh and Sanandaj are higher 5 branches regarding the scale and technical productivity, and the branches of Meidan-E-Bar Sanandaj, Bazar Bijar Jomhuri Street of Marivan are of non-productive branches of Keshavarzi banks in Kurdistan Province. Also, based on these results of hierarchical analysis of the data (AHP), the efficiency of deposits was 0.633 , delivered facilities was 0.287 and income was 0.08 .

Keywords: Scale productivity, Technical productivity, Data Envelopment Analysis, CCR model , BCC model

\section{Introduction}

The banking system of our country has a effective role as one of the most important sections of social economy in fundraising and leading depositor's fund, providing services and facilities to people and participating in economical, social and cultural development and incapability of this system would cause numerous problems in the path of the development of the country. In one hand, multitude economical experts believe that the most important and fundamental issue of Iran banking system is the state of banking system and this characteristic leads the banking system to incapability in providing the country macro economical goals. On the other hand, about half a decade has passed since the beginning of private banks activities in our country and this period of time could be considered as a precious experience in creating a competitive atmosphere in the region of the banking system.

In all over the world operations of the banks have been considered as one of the important economical activities of each economical system. Each activity that demands in receiving fund and financial resources, Undoubtedly would demand the interference of the banking system and financial organizations. Due to the important and fundamental role of the banking system in most of the economical activities, study of the functionality of each existing bank in Iran banking system-which most of them are state banks and were funded by national capitals and resources- has gained so much importance like any other economical organizations and public sector. But according to service based activities of the banks and the variety of provided services by them, evaluating their function has its own special issues and methods which demands more accuracy and use of more efficient methods. Originally, considering the current and future economical circumstances, management of the banks bank needs a dynamic reformation and development in its services, marketing, budgeting, competing with other banks and finally developing its efficiency and functionality among its covering units. One of the basic ways in the success of the banks for correcting service production methods and increasing competitive power with their banks is the network of their branches. One of the basic methods in regulating efficiency development programs in the level of one bank, is a functional network of branches (Athanasopoulos ,1997)

In the current circumstances, by considering the wide span of bank branches all over the country, founding new financial and credit, establishment of new private banks, entering foreign banks to the country via free zones and finally privatization of banks in Iran, all caused a rare and new situation to take place which demands a basic study and a efficient reformation in the network of the branches of commercial and professional banks in the country. To meet this 
goal it is necessary for each bank to have full information about the efficiency of their branches and analyze the factors of efficiency and inefficiency of each one of them and by suitable programming start to correct and lead their inefficient units. It is obvious that by changing inefficient branches to efficient ones not only these goals will be achieved and price of provided services will reduce, but also it can be expected that more financial resources will be supplied and in the general level of a bank losses from inefficiency fall to the lowest point and totally the country banking system will be more efficient. for this purpose 42 branches of Keshavarzi bank in Kurdistan province have been evaluated and the efficient and inefficient branches will be highlighted

\section{Statement of the Problem}

In today competitive world the main factor for durability and existence of all economical organizations is the development in the level of their efficiency, banks as the directors of monetary section of economy and due to the high rate of the reflections of the policies in the society, they have more effective role in create and keep a constant and stable economic growth. In order to provide more different, modern and faster services and competition possibility and to remain in the various wave of informing and service development all over the world, these institutes need constant evaluation of their units and renewing their organizing according to withdrawn results from multiple analyzes. In the meantime, according to service based activity of the banking system and the variety of their provided services evaluating their function has its own complexity.

Considering the current and future economical circumstances, management of the banks bank needs a dynamic reformation and development in its services, marketing, budgeting, competing with other banks and finally developing its efficiency and functionality among its covering units. One of the basic ways in the success of the banks for correcting service production methods and increasing competitive power with their banks is the network of their branches. One of the basic methods in regulating efficiency development programs in the level of one bank, is a functional network of branches.

In the current circumstances, by considering the wide span of bank branches all over the country, founding new financial and credit, establishment of new private banks, all caused a rare and new situation to take place which demands a basic study and a efficient reformation in the network of the branches of commercial and professional banks in the country. To meet this goal, it is necessary for each bank to have full information about the efficiency of their branches and analyze the factors of efficiency and inefficiency of each one of them and by suitable programming start to correct and lead their inefficient units. It is obvious that by changing inefficient branches to efficient ones, in addition to provide better services to customers of each branch, the losses caused from inefficiency will fall to the lowest point.

\section{Research Hypotheses}

First hypothesis: Keshavarzi bank branches in Kurdistan province have the sufficient technical efficiency. Second hypothesis: Keshavarzi bank branches in Kurdistan province have the sufficient scale efficiency.

\section{Objective of the Study}

Regarding the focus of this study, the main objective is to determine the performance of Keshavarzi bank branches in Kurdistan province and rate these branches base on their efficiency. With regard to the minor objective, the following can be mentioned:

- Determining scale efficiency level in the studied branches

- Determining technical efficiency level in the studied branches

- Rating and prioritizing branches base on their technical and scale efficiency

\section{Efficiency and Effectiveness}

One of the programs shared between all levels of management is planning. If this program is performed in the higher levels of an organization according to the general purposes and guidelines of that organization in a long term period it is called "comprehensive planning" or "strategic planning". But, if this practice happens in the middle layers of an organization or in its fundamental levels and focuses on the current purposes of the organization following old and experienced methods, it will be called "operational planning". Now, if the "operational planning" of the organization should be studied, and the levels of their realization should be evaluated, both these practices will determine the 
efficiency of that organization under the effectiveness of "comprehensive" or "strategic planning". "by effectiveness it means to determine main and basic purposes and to achieve them, but the term efficiency means to achieve determined purposes or to reach to the highest amount of output".(Alvani,1990.p15). Or ,by the other means, "effectiveness means to do the right things and efficiency means to do things right"(Alagheband,2001). Efficiency shows the conversion ratio of converting inputs to outputs, and effectiveness is the connection ratio between outputs with purposes. And, productivity is the vector sum of efficiency and effectiveness that shows how an organization use its resources to achieve their purposes. Now, if we define efficiency as doing thing right and effectiveness as doing the right thing, so, productivity could be defined as doing the right thing right.

Efficiency means to use the available facilities to achieve the best outcome, and effectiveness means to have desired outcome and productivity deals with the ratio between the input and the outcome. So, outcome equals with the effectiveness and input equals the meaning of the efficiency. Therefore, the concept of productivity is a mixture of effectiveness and efficiency.

\section{Concept of efficiency in Data Envelopment Analysis (DEA)}

Efficiency of a unit depends on the comparison between inputs and the output of that unit. In its simplest and the earliest form in which there is only one input and one output , productivity could be attained by dividing output to input

\section{Productivity $=\frac{\text { output }}{\text { input }}$}

For example, the efficiency of a computer will be attained by dividing the number of calculations into the time which shows the number of calculations per unit of time.

If the decision making unit have multiple inputs with defined value(price)for each one of them, it is possible to calculate the efficiency by dividing the amount of product of outputs with respective weights(price or value) into the amount of the product of inputs in with respective weights(price or value).

$$
\text { Efficiency }=\frac{\text { Total weight of the amount of outputs(2) }}{\text { Total weight of the amount of inputs(1) }}
$$

\section{Calculating the Efficiency of Banking System in Iran with Using Data Envelopment Analysis (DEA)}

This research has been done with the aim to calculate technical, allotment and economical efficiency of ten state bank in Iran including Meli, Saderat, Tejarat, Mellat, Sepah, Refah, Tose-E-Saderat, Maskan, Keshavarzi and Sanat Va Madan for the period of 1999-2009.

The inputs of this research include:

A)The number of employees B)Amount of inputs C) Fixed assets amount

And the outputs are:

A) Concessional loans in the form of Islamic contracts

B) Concessional loans in the form of business law

The outcome results from this research shows that only seven bank out of ten including : Meli, Tose-E-Saderat, Keshavarzi, Sanat VA Madan, Saderat, Maskan and Refah have the technical, allotment, and economical efficiency and Tose-E-Saderat only has the technical efficiency.

The general results also show that the technical and economical efficiency of the banks in the year 1999 is more than 1997 and 1998 and allotment efficiency have been almost fix and stable during these three years. The average technical, allotment and economical efficiency of these banks during these three years in the order were 86.4, 84.5 and 74.4 percent. In the other word, the banking industry have experienced 13.2 percent of technical inefficiency, 15.5 percent of allotment inefficiency and 25.6 of economical inefficiency.

\section{Research Method}

In this research Descriptive research method and survey research method were used. this research is also a practical research based on the aim of research.

\subsection{Statistic sample}

In this research due to the fact that all of the Keshavarzi bank branches in Kurdistan province were studied, there is no need to do any sampling, therefore, no special sampling method was used. based on the given information by the 
administration of Keshavarzi banks of the Kurdistan province there are 42 branches in this province.

\subsection{Data collecting method}

1) Recognizing and determining the inputs: prices, personnel input, capital, branches equipments.

2) Recognizing and determining the outputs: types of incomes, types of deposits, types of facilities, the number of bank main services.

These data were achieved in two following steps:

A) Setting Tables and forwarding them to branches in order to collect input and output.

B) Setting Tables in order to achieve the weight of inputs and outputs by using the opinion of experts from Keshavarzi bank with using the Delphi technique

The process of evaluating the performance of the branches in this study includes following steps:

1. Recognizing the purposes of the evaluation

2. Determining inputs and outputs

3. limiting the weights of the researches

4. Choosing DEA models to achieve the purposes of the evaluation

5. Choosing the software to solve the models

6. Solving the models and analyzing the results

\section{Analyzing the Results from the Models}

Efficiency rates from CCR and BCC models are provided in Table number one:

Table 1: Branches efficiency rate based on research models

\begin{tabular}{|c|c|c|c|}
\hline DMU code & Branch name & Efficiency rate based on CCR model & Efficiency rate based on BCC model \\
\hline 1 & Civil Divandare & 0.7765 & 0.6197 \\
\hline 2 & Marivan Resallat & 0.7117 & 0.5768 \\
\hline 3 & Sanandaj Bazar & 0.8596 & 0.6157 \\
\hline 4 & Sarvabad & 1 & 0.9014 \\
\hline 5 & Hossein Abad sanandaj & 1 & 0.9112 \\
\hline 6 & Hasan Abad Sananjaj & 1 & 0.9568 \\
\hline 7 & Shavisheh & 0.8578 & 0.7179 \\
\hline 8 & Ta'avon Sanandaj & 0.8493 & 0.6991 \\
\hline 9 & Meidan-E-Baar Sanandaj & 0.7487 & 0.5947 \\
\hline 10 & Mohajerin Ave Sanandaj & 0.8019 & 0.6569 \\
\hline 11 & Enghelab Ave Sanandaj & 1 & 1 \\
\hline 12 & Jahad Sanandaj & 1 & 0.9537 \\
\hline 13 & Saheb & 1 & 1 \\
\hline 14 & Hasan Abad Yasukand & 1 & 1 \\
\hline 15 & Babarashani & 1 & 1 \\
\hline 16 & Vinsar & 1 & 0.991 \\
\hline 17 & Dezaj & 1 & 1 \\
\hline 18 & Molavi Kurd & 1 & 1 \\
\hline 19 & Gharochai & 1 & 0.9892 \\
\hline 20 & Dehgolan & 1 & 1 \\
\hline 21 & Kamyaran Emam Ave & 0.9224 & 0.8587 \\
\hline 22 & Mochesh & 1 & 0.9763 \\
\hline 23 & Kamyaran & 1 & 1 \\
\hline 24 & Kaani Soor & 0.7563 & 0.6014 \\
\hline 25 & Baneh & 1 & 1 \\
\hline 26 & Zarineh Avbano & 1 & 0.9431 \\
\hline 27 & Divandareh & 1 & 1 \\
\hline 28 & Marivan Jomhuri Ave & 0.7271 & 0.5417 \\
\hline 29 & Marivan & 1 & 1 \\
\hline 30 & Ghorveh Azadi Square & 0.8319 & 0.6813 \\
\hline
\end{tabular}




\begin{tabular}{|c|l|c|c|}
\hline 31 & Delbaran & 0.8897 & 0.7515 \\
\hline 32 & Sarish Abad & 1 & 1 \\
\hline 33 & Ganji & 1 & 0.9913 \\
\hline 34 & Ghorveh & 1 & 1 \\
\hline 35 & Shir Sanandaj & 0.9563 & 0.8914 \\
\hline 36 & Sanandaj & 1 & 1 \\
\hline 37 & Saghez Jomhuri Square & 0.7824 & 0.6361 \\
\hline 38 & Saghez & 1 & 1 \\
\hline 39 & Bijar Bazar & 0.7377 & 0.5831 \\
\hline 40 & Khosro Abad & 0.8769 & 0.7214 \\
\hline 41 & Najaf Abad & 0.8931 & 0.7812 \\
\hline 42 & Bijar & 1 & 1 \\
\hline
\end{tabular}

As it seems in the table number one, 25 out of 42 branches has been identified as efficient base on CCR model. And base on BCC model only 16 branches has been identified as efficient branches.

In fact, it could be said that 25 branches from all Keshavarzi bank branches in Kurdistan province has the technical efficiency and 16 of them has the scale efficiency in addition to technical efficiency.

The results from this model give the answer to the research hypotheses which determines that which branches have the technical and scale efficiency. In fact, some of these branches have both technical and scale efficiency, while some others have the technical efficiency but lack the scale efficiency. And, there are some branches which have neither the technical efficiency nor the scale efficiency. Their names are in the following table

Table 2. Branches' status base on having technical and scale efficiency

\begin{tabular}{|c|c|c|c|c|}
\hline Branch name & Having technical efficiency & Having scale efficiency & Lack of technical efficiency & Lack of scale efficiency \\
\hline Ghorveh & * & * & & \\
\hline Dehgolan & * & * & & \\
\hline Bijar & * & * & & \\
\hline Divandareh & * & * & & \\
\hline Sanandaj & * & * & & \\
\hline Kamyaran & * & * & & \\
\hline Saheb & * & * & & \\
\hline Molavi Kurd & * & * & & \\
\hline Dezaj & * & * & & \\
\hline Saghez & * & * & & \\
\hline Baneh & * & * & & \\
\hline Sarish Abad & * & * & & \\
\hline Marivan & * & * & & \\
\hline Babarashani & * & * & & \\
\hline Sanandaj Enghelab Ave & * & * & & \\
\hline Hasan Abad Yasukand & * & * & & \\
\hline Ganji & * & & & * \\
\hline Vinsar & * & & & * \\
\hline Gharochai & * & & & * \\
\hline Mochesh & * & & & * \\
\hline Hasan Abad Sanandaj & * & & & * \\
\hline Jahad Sanandaj & * & & & * \\
\hline Zarineh Avbano & * & & & * \\
\hline Hossein Abad Sanandaj & * & & & * \\
\hline Sarv Abad & * & & & * \\
\hline Shir Sanandaj & & & * & * \\
\hline Kamyaran Emam Ave & & & * & * \\
\hline Najaf Abad & & & * & * \\
\hline Delbaran & & & * & * \\
\hline Khosro Abad & & & * & * \\
\hline Shavisheh & & & * & \\
\hline
\end{tabular}




\begin{tabular}{|l|l|l|c|c|}
\hline Ta'avon Sanandaj & & & ${ }^{*}$ & ${ }^{*}$ \\
\hline Ghorveh Azadi Square & & & ${ }^{*}$ & ${ }^{*}$ \\
\hline Bazar Sanandaj & & & ${ }^{*}$ & ${ }^{*}$ \\
\hline Sanadaj Mohajerin Ave & & & ${ }^{*}$ & ${ }^{*}$ \\
\hline Saghez Jomhuri square & & & ${ }^{*}$ & ${ }^{*}$ \\
\hline Civil Divandareh & & & ${ }^{*}$ & ${ }^{*}$ \\
\hline Kaani Soor & & & ${ }^{*}$ & ${ }^{*}$ \\
\hline Meidan-E-Baar Sanandaj & & & ${ }^{*}$ & ${ }^{*}$ \\
\hline Bijar Bazar & & & \\
\hline Resallat Marivan & & & & \\
\hline MArivan Jomhuri Ave & & & & \\
\hline
\end{tabular}

\section{Conclusion and Recommendations}

Based on CCR model the number of 25 out of 42 studied branches(covering all Keshavarzi bank branches in Kurdistan province) are identified as efficient branches and based on BCC model there are only 16 efficient branches among 42 . In fact, it could be sad that 25 branches from all Keshavarzi bank branches in Kurdistan province have the technical efficiency and 16 of them have both technical and scale efficiency.

These branches are ranked based on Friedman test from which the results shows that Ghorveh, Dehgolan, Bijar, Divandareh and Sanandaj are ranked as top 5 branches according to tehnical and scale efficiency and Kaani Soor, Meidan-E-Bar Sanandaj, Bijar Bazar, Resallat Marivan And Marivan Jomhuri Square are at the bottom of the table and are from the inefficient branches of Keshavarzi bank in Kurdistan province.

Based on the results, the following recommendations can be raised:

1- Since based on CCR model 25 branches of Keshavarzi bank in Kurdistan province hve the enough technical efficiency, assuming output to the fix scale, it is suggested that due to the competitive atmosphere of banking industry (private and state banks and also credit institutions) Keshavarzi bank should not be dependent only on current situation and it should look forward to more developments and reinforce current abilities. And this purpose will be attained by providing newer services, training personnel and equipping them to update science and improving the way they deal with the customers and clients.

2- Since there are multiple inner and environmental factors in the banking industry which affect an their efficiency ,therefore, output to variable scale assumption has more scientific credit. And this fact sets an alarm for the branches of Keshavarzi bank to notice them that only 16 branches out of 42 have the scale efficiency, therefore, it is suggested that to keep these 16 branches in the competitive atmosphere more attention should be given on performing the optimization steps which have been told above.

3- As it was explained based on CCR model 17 branches and based on Bcc model 26 branches out of 42 lack the technical or scale efficiency or a mixture from the lack of both of them which urge some analyzing to be performed in order to recognize the factors which caused the inefficiency of these branches and further to solve them. If internal factors caused this inefficiency, this should be solved by using special methods and if environmental factors are dealing with this inefficiency and these factors are beyond the power of Keshavarzi bank to be controlled, bank administrations should stop the activity of that branch.

\section{References}

Alirezaee. M. R., (2005), The overall assurance interval for the non-Archimedean Epsilon in DEA models; a partition base algorithm, Applied Mathematics and Computations 164,667-647

Athanasios G.Noulas \& Niki Glaveli (2001). Bank Branch Efficiency : An Application of DEA Analysis, http://www.efmeafm.org/Glavelinki. Jahanshloo , G.R., \& Alirezaee , M.R. (1997). Tutorial on Data Envelopment Analysis, Proceeding of 28th AIMC, Tabriz University.

Kirikal. L., Sõrg. M., \& Vensel. V. (2004). Estonian Banking Sector Performance Analysis Using Malmquist Indexes And DuPont Financial Ratio Analysis". International Business \& Economic Research Journal. 3(12), 21-36

Motameni. A.R. (2002). Dynamic model of efficiency with DEA approach, Ph.Ds thesis, Tarbiat Modares University.

Shabahang. R. \& Borhani. H. (1998). Measurement the efficiency of commercial banks and its relationship with organizational and financial aspects of Economics and Management, 37-38. 